\title{
Identifying causes of ground-penetrating radar reflections using time-domain reflectometry and sedimentological analyses
}

\author{
Remke L. Van Dam \& Wolfgang Schlager \\ Department of Sedimentology, Faculty of Earth Sciences, Vrije Universiteit, De Boelelaan \\ 1085, 1081 HV Amsterdam, The Netherlands.
}

This work is published in Sedimentology. Please cite as:

Van Dam, R. L. and Schlager, W. (2000), Identifying causes of ground-penetrating radar reflections using time-domain reflectometry and sedimentological analyses. Sedimentology, 47: 435-449. doi:10.1046/j.1365-3091.2000.00304.x

A type-set and proofed version of the paper is available upon request. 


\begin{abstract}
Although electromagnetic theory is well understood, little is known about the exact cause of radar reflections in sediment. To obtain detailed information on the radar-wave contrast parameter in the subsurface 100 and $200 \mathrm{MHz}$ radar surveys of eolian deposits in a quarry were combined with time-domain reflectometry (TDR). Combining lacquer peels and TDR data from the quarry wall allowed identification of relationships between sediment characteristics and electromagnetic wave velocity. Peaks in the product of relative permittivity and relative magnetic permeability (inversely proportional to electromagnetic wave velocity) which are superimposed on a baseline value for dry sand, are caused by potential radar reflectors. These peaks coincide with the presence of either organic material, having a higher water content and relative permittivity than the surrounding sediment, or iron-oxide bands, causing water to stagnate and possibly enhancing relative magnetic permeability. Sedimentary structures, as reflected in textural change, only result in possible radar reflections when the pores contain capillary water. Synthetic radar traces, constructed using the TDR logs and sedimentological data from the lacquer peels, provide an improved insight into the behavior of radar waves and show that radar results may be ambiguous because of multiples and interference.
\end{abstract}

\title{
INTRODUCTION
}

The seismic reflection method and ground-penetrating radar (GPR) are important geophysical reconnaissance tools for the shallow subsurface. Both techniques are based on wave propagation and reflection, but wave length ranges, and consequently resolution and penetration depths, differ significantly. The seismic reflection method has a better penetration but lower resolution than GPR. Also, the contrast parameter for the seismic reflection method (acoustic impedance) differs from that for GPR (dielectric impedance). Yet, the two techniques are sufficiently analogous for experience gained with the one to be applicable to the other, increasing our knowledge on the origin and interpretation of reflections in both the seismic reflection method and GPR (Cardimona et al., 1998).

In the seismic reflection method, most reflections of sedimentary deposits are parallel to depositional bedding. Two different types of reflection exist (Mayer, 1980): (1) reflections that occur at the location of major changes in acoustic impedance; and (2) reflections that represent patterns resulting from constructive and destructive interference between the acoustic wave train and small impedance variations in the sediments or rocks. Only the first type of reflection serves as a reliable guide to depositional history and geometry and its amplitude is proportional to the magnitude of change. In contrast, the second type of reflection does not represent a major impedance change at the measured travel time (Mayer, 1979). An important method for distinguishing these two reflection types is detailed comparison of seismic traces 
with sediment and rock properties, as determined from cores and outcrop studies. These outcrop studies are conducted in deposits that are considered to be analogous, or on exposures in the vicinity of the seismic line (Stafleu and Sonnenfeld, 1994). The sediment and rock properties from the outcrop studies can be used to generate lithologic and acoustic impedance models and are widely used to construct synthetic seismic traces and sections (Bracco Gartner and Schlager, 1999; Fagin, 1991; Stafleu and Schlager, 1995). These synthetic images improve the understanding of seismic sections and reflections. It cannot be assumed, however, that the rock and sediment properties measured in outcrops are completely similar to those reflected in the seismic trace.

GPR measures changes in the dielectric properties of sediments that cause reflection of electromagnetic energy. These changes in dielectric properties result primarily from changes in water content, governed in turn by grain-size and porosity (Huggenberger, 1993; Roth et al., 1990; Sutinen, 1992; Topp et al., 1980). Since grainsize and porosity changes are related to depositional history, a clear relationship can be expected between sedimentary structures and dielectric properties, allowing accurate identification of radar facies and sequence boundaries (Gawthorpe et al., 1993).

Most work with GPR has focused either on geological and sedimentological reconnaissance (Asprion and Aigner, 1997; Beres et al., 1995; Bridge et al., 1998; Bristow et al., 1996; Huggenberger, 1993; Jol and Smith, 1991; Van Heteren et al., 1998; Van Overmeeren, 1998; Neal and Roberts, 2000) or on synthetic modeling of wave propagation (Carcione, 1996; Casper and Kung, 1996; Hollender and Tillard, 1998). Studies in which wave theory is integrated with geological or petrophysical data, common in reflection seismics, are sparse. As a result, little qualitative and quantitative knowledge exists on the cause of GPR reflections. GPR shows sedimentary structures and other features in the subsurface, but no information is available on the origin of reflections or on the behavior of the contrast parameter, other than from the reflection image (and its parameters, such as reflection strength). However, many dielectric impedance changes are beyond the resolution and sensitivity range of GPR. For a full understanding of the origin of GPR reflections, dielectric impedance variations smaller than those observed on radar images must be analyzed and explained.

In this study, time-domain reflectometry (TDR), a technique well known in soil sciences (Heimovaara et al., 1995; Topp et al., 1982), was used to correlate GPR data with subsurface information by measuring dielectric properties of sediment at small intervals along vertical sections in a quarry. TDR measures the propagation velocity of an electromagnetic wave along a steel-rod probe that is pushed into the sediment, and is best applied in unconsolidated sand-sized and finer sediments. In coarse grained sediment the TDR method functions worse due to disturbance of the sediment fabric during the penetration of the TDR rods. The TDR measurements were interpreted using detailed sedimentological information from lacquer peels and grain-size analyses, providing insight into the possible causes of GPR reflections. Based on the TDR logs and the sedimentological information from the lacquer peels, a dielectric impedance model of the subsurface was constructed. This model, in which the sediment column is 
subdivided into distinct layers with characteristic dielectric properties, was used to construct 1-D synthetic radar traces. In analogy to the seismic reflection method, such synthetic images can be compared with real GPR sections for a better understanding and quantification of parameters controlling GPR reflections. Ultimately, such comparisons will improve the knowledge of waves and their reflections in general, which may also benefit the seismic reflection method.

\section{ELECTROMAGNETIC WAVE THEORY}

The techniques of ground-penetrating radar (GPR) and time-domain reflectometry (TDR) are based on propagation and reflection of electromagnetic energy in the subsurface. The (frequency-dependent) properties that control the behavior of electromagnetic energy in a medium are dielectric permittivity $(\varepsilon)$, where $\varepsilon=\varepsilon_{0} \varepsilon_{r}$, electrical conductivity $(\sigma)$, and magnetic permeability $(\mu)$, where $\mu=\mu_{0} \mu_{r}$ (Von Hippel, 1954). Here, $\varepsilon_{0}$ is the permittivity of vacuum $\left(8.85419 \cdot 10^{-12} \mathrm{Fm}^{-1}\right), \varepsilon_{r}$ is the relative permittivity, $\mu_{0}$ is the magnetic permeability of vacuum $\left(4 \pi 10^{-7} \mathrm{Hm}^{-1}\right)$, and $\mu_{r}$ is the relative magnetic permeability. Together, these properties define the dielectric impedance $(Z)$ of the medium for harmonic electromagnetic waves with $\exp (j \omega t)$ dependence (Brewster and Annan, 1994; Fokkema et al., 2001):

$$
Z=\left(\frac{j \omega \mu}{\sigma+j \omega \varepsilon}\right)^{1 / 2}
$$

where $j=\sqrt{-1}, \omega=2 \pi f$ is angular frequency (radians. $\mathrm{s}^{-1}$ ), and $t$ is time (s). A range of electromagnetic properties for common geologic materials can be found in Davis and Annan (1989) and in Van Heteren et al. (1998). For most geological materials, the relative magnetic permeability $\left(\mu_{r}\right)$ is near unity (Roth et al., 1990). Consequently, the magnetic permeability in the subsurface is near the free-space value $\left(\mu_{0}\right)$ and plays no role in the electromagnetic energy behavior (Powers, 1997). However, under certain conditions, such as the presence of iron and iron oxides, relative magnetic permeability can be enhanced significantly (Olhoeft and Capron, 1994; Von Hippel, 1954). In most natural low-loss material such as clean sand, the influence of $\sigma$ on the electromagnetic signal is negligible between 100 and $1000 \mathrm{MHz}$ (Davis and Annan, 1989). In contrast, the relative permittivity plays an important role in both propagation and reflection of electromagnetic waves (Huggenberger, 1993). Because water has a relative permittivity of around 80, whereas air and quartz have values of 1 and around 4.3, respectively, the relative permittivity of sediment is governed by its water content.

The propagation velocity $(v)$ of electromagnetic waves in a medium is found by: 


$$
v=\frac{c_{0}}{\left[\varepsilon_{r} \mu_{r}\left(\frac{1+\sqrt{1+(\sigma / \omega \varepsilon)^{2}}}{2}\right)\right]^{1 / 2}},
$$

where $c_{0}$ is the electromagnetic wave velocity in vacuum $\left(3 \cdot 10^{8} \mathrm{~ms}^{-1}\right)$ and $(\sigma / \omega \varepsilon)^{2}$ is a loss factor. For common geological material, the influence of the conductivity $(\sigma)$ on the electromagnetic wave velocity is negligible over the entire GPR frequency range (Davis and Annan, 1989) and the loss factor approaches zero. Consequently, the velocity is mainly controlled by $\varepsilon_{r}$ and $\mu_{r}$ and equation (2) can be simplified by:

$$
v=\frac{c_{0}}{\sqrt{\varepsilon_{r} \mu_{r}}},
$$

which reduces to:

$$
v=\frac{c_{0}}{\sqrt{\varepsilon_{r}}}
$$

assuming relative magnetic permeability $\left(\mu_{r}\right)$ is near unity.

Attenuation of electromagnetic signals is governed by $\sigma$ and $\varepsilon_{r}$. In low-loss material, the original pulse amplitude $\left(A_{0}\right)$ decreases exponentially with depth $(z)$ according to $A=A_{0} \cdot e^{-\alpha \cdot z}$, where the attenuation constant $\alpha=0.5 \sigma \cdot(\mu / \varepsilon)^{1 / 2}$ (Theimer et al., 1994). This relationship is valid only for homogeneous sediments without impedance contrasts. When a propagating electromagnetic wave encounters a discontinuity in electric, magnetic or conductive properties, part of the electromagnetic energy is reflected, the reflection strength being proportional to the magnitude of change. For a perpendicular incident wave, coming from a medium characterized by a wave impedance $Z_{1}$ and going to a medium with impedance $Z_{2}$, the reflection coefficient $(R C)$ is expressed as (Brewster and Annan, 1994):

$$
R C=\frac{Z_{2}-Z_{1}}{Z_{2}+Z_{1}}
$$

With the same parameters present in the calculations of dielectric impedance (equation (1)) and electromagnetic wave velocity (equation (2)), velocity contrasts can be taken as a measure for contrasts in dielectric impedance. If one assumes $\sigma$ insignificant and contrasts in $\mu$ negligible, equation (5) can be rewritten as: 


$$
R C=\frac{\sqrt{\varepsilon_{r 2}}-\sqrt{\varepsilon_{r 1}}}{\sqrt{\varepsilon_{r 2}}+\sqrt{\varepsilon_{r 1}}} .
$$

\section{METHODS}

\section{Ground-penetrating radar}

In this study, a Sensors\&Software pulseEKKO100 GPR system, consisting of a transmitting and receiving antenna connected to a console and laptop computer (Figure 1a) was used. The transmitted electromagnetic pulse is ideally meant to penetrate the subsurface in a beam as narrow as possible. Some of the energy, however, travels directly to the receiving antenna as airwave and groundwave, giving the signal at the top of the resulting radar section (Figure 1b). Part of the remaining energy, which enters the subsurface, reflects at layers of changing dielectric impedance and travels back to the receiver. The quantity of energy received and the associated arrival time are stored in the computer. The lateral extent and morphology of reflectors can be delineated by moving the portable equipment across the surface. The resulting radar section, on which each measurement point is represented by a trace, shows time along its vertical axis and position along its horizontal axis. The velocity of radar waves in different layers can be calculated through common-mid-point (CMP) measurements (Arcone, 1984), allowing conversion of travel time to actual depth.

The electrical conductivity of a material influences penetration depth as well as resolution. Low-conductivity materials, such as unsaturated and coarse-grained sediments, cause little attenuation and under ideal circumstances, penetration is on the order of tens of meters (Davis and Annan, 1989). However, wave velocity and length are highest in low conductivity materials, leading to a decrease in resolution (Table 1). Penetration depth and resolution are also influenced by the GPR frequency used for measurement. Lower antenna frequencies are favorable for greater penetration, but result in a decrease in resolution. Resolution is commonly assumed to be a quarter of the GPR wave length, and ranges from $2 \mathrm{~cm}$ for saturated sands and 900-MHz antennas to $40 \mathrm{~cm}$ for dry sands and 100-MHz antennas (Table 1).

\section{Time-domain reflectometry}

The TDR method is based on the propagation velocity of an electromagnetic signal along a sediment probe, and was developed to characterize the water content of soils using the relative permittivity (Topp et al., 1980). Assuming variations in $\sigma$ are negligible, the propagation velocity can be calculated from equation (3). The product of the relative permittivity and the relative magnetic permeability is calculated from the travel time $\left(\Delta t_{s}\right)$ of the TDR signal and the length $\left(L_{p}\right)$ of the probe (Roth et al., 1990): 


$$
\varepsilon_{r} \mu_{r}=\left(\frac{c_{0} \Delta t_{s}}{2 L_{p}}\right)^{2}
$$

Factors other than water content, such as soil density, texture and temperature, have a negligible influence on the relative permittivity (Topp et al., 1980). Using these assumptions and $\mu_{r}=1$, the volumetric water content $(\theta)$ is found by substitution of $\varepsilon_{r}$ in the empirical relationship (Topp et al., 1980):

$$
\theta=-5.3 \cdot 10^{-2}+2.92 \cdot 10^{-2} \varepsilon_{r}-5.5 \cdot 10^{-4} \varepsilon_{r}^{2}+4.3 \cdot 10^{-6} \varepsilon_{r}^{3}
$$

Early laboratory studies (e.g., Fellner-Feldegg, 1969) used sediment columns in coaxial transmission lines, whilst field probes were later developed and improved (Brisco et al., 1992; Dalton et al., 1984; Heimovaara, 1993; Zegelin et al., 1989). In this study, the TDR equipment developed by Heimovaara and Bouten (1990) was used (Figure 2a). A 0.05-m-long, three-rod probe, connected to a Tektronix cable tester and laptop computer for system control and data storage, was pushed into the sediment. The cable tester transmits a fast-rise voltage pulse through the transmission line and probe. The frequency band ranges from $300 \mathrm{kHz}$ to $3 \mathrm{GHz}$ (Heimovaara et al., 1996), which encompasses all GPR frequencies. At changes in electrical properties, part of the pulse is reflected to the cable tester. After calibration for the epoxy casing, the two reflection points of the resulting wave form (Figure 2c) give the travel time along the rods $\left(\Delta t_{s}\right)$, necessary to obtain $\varepsilon_{r} \mu_{r}$ (Equation (7)).

\section{Sedimentological and textural characteristics}

Sedimentary structures were studied both directly in the field and by using lacquer peels and thin sections. The lacquer peels were made to study sedimentary structures and parameters macroscopically. On these lacquer peels, sedimentary structures or bedding planes appear as narrow ridges or lows, owing to different grain and pore sizes. Other elements, like organic material and iron oxide, appear as (root) relicts or as color changes on the lacquer peel. Thin sections, made from undisturbed sediment samples, were used to study sediment properties microscopically. Two samples were taken for grain-size analyses.

\section{Synthetic radar traces}

Using TDR and sedimentological data, dielectric impedance models of the subsurface can be constructed. The models, in which values for depth and $\varepsilon_{r} \mu_{r}$ are given, form the input for pulseEKKO software (Sensors\&Software, 1996) that constructs synthetic GPR traces. The program assumes vertically incident electromagnetic waves and calculates all generated reflections, including multiples and interlayer reflections. The program does not account for frequency dependence of electromagnetic properties. Therefore, any possible wave dispersion as a result of 
variations in velocity and attenuation within the transmitted frequency bandwidth is not modeled. Firstly, the program transforms the impedance model from a depth scale into a time scale. Then, the impulse response for the layered model is computed and a correction for spherical-waveform spreading losses is applied. The ground response is obtained by convolution of a standard pulseEKKO wavelet (both 100 and $200 \mathrm{MHz}$ ) with the impulse response. Attenuation differences and dispersion were not incorporated into the model. To ensure that small reflections were also visualized, the 1-D synthetic traces were plotted with an automatic gain control (AGC), applying a gain inversely proportional to the signal strength. A gain limit was applied to prevent very small signals from producing very large gains.

\section{SEDIMENTOLOGY AND STRATIGRAPHY OF THE STUDY SITE}

Fieldwork was conducted in the Boudewijn quarry in Ossendrecht (Figure 3). This 15-m-deep quarry can be subdivided into two units; a lower unit of tidal deposits and an upper unit of eolian deposits.

The lower unit has a thickness of approximately $7.5 \mathrm{~m}$ and consists of tidal sediments (Tegelen Formation) deposited during several Tiglian interglacials of Early Pleistocene age (Kasse, 1988; Figure 4). An unconformity, possibly formed during the regression associated with the Beerse Glacial, separates two subunits. The lower subunit (Hoogerheide Member) consists of large-scale cross-bedded very fine to fine sand. Locally, numerous small ripple marks with clay drapes, resulting from frequent flow reversals, are present (Kasse, 1988). The upper subunit (Woensdrecht Member) consists of large-scale cross-bedded very fine to medium sand. The top of this subunit is a laterally continuous clay layer with a maximum thickness of $3 \mathrm{~m}$ (Kasse, 1988). At the end of the Tiglian interglacial, the climate became cooler and sea level fell. As a result, a substantial hiatus, locally marked by a coarse-grained residual deposit, is present on top of the Woensdrecht member at the base of the upper eolian unit. This hiatus represents an extended time of erosion and non-deposition (Kasse, 1988).

The upper quarry unit has a maximum thickness of $7.5 \mathrm{~m}$ and consists of eolian sands of the Pleistocene Twente and Holocene Kootwijk Formations (Kasse, 1988). These formations are separated by a peat layer of the Griendtsveen Formation in blowout hollows or by a paleosol of Podsol type in adjacent higher areas (Figure 4). The sand from the Twente Formation dates from the Late Dryas Stadial to the Early Holocene (Schwan, 1991). Locally, a thin soil or peat layer from the Allerød Interstadial is present near the bottom of this subunit. The sand from the Twente Formation originates from the banks of the river Scheldt, which flowed just to the west of the study area (Figure 3). This sand was deposited as sand sheets and dunes and has a large- to medium-scale cross-bedded character. The prominent peat bed and paleosol separating the Twente and Kootwijk Formations represents most of the Early- and Middle Holocene, a timespan of approximately 6000 years (Schwan, 1991). Deposition of the sand from the Late-Holocene Kootwijk Formation started as early as 3000 years 
ago through buildup of small dunes (Schwan, 1991). In places, lamination has been obliterated by abundant roots that can be assigned to several discontinuous soil levels.

The steplike excavation of the quarry would have allowed investigation of all units, both from the top and the side wall. In this study, a section in the eolian unit was chosen for detailed analysis (Figure 5) because: (1) it is made up of highly resistive sand; (2) the paleosol between the two eolian subunits, and the transition to the Tegelen clay at the base of the eolian sand, were expected to give clear GPR reflections and provide good reference points in the radar sections; (3) the variety of sedimentary structures was considered important in establishing which features cause reflection of GPR waves; and (4) the terrain at this site was easily accessible and even.

The schematic representation of sedimentary and pedogenic structures in the studied section (Figure 5b), reflects the general stratification for the upper quarry unit given above. In the section studied, the Allerød soil is absent. Three inorganic facies, deposited on a gradually drying depositional surface (Schwan, 1991), comprise the Twente Formation: (1) a basal sub-horizontally bedded sand-sheet facies, (2) a gently dipping sand-sheet facies and (3) a cross-stratified dune facies. Sand-sheet facies B, at the base of the formation, is characterized by alternation of medium sand and finergrained beds. This facies reflects a varying wind regime, a damp depositional surface (caused by the underlying semi-pervious Tegelen Formation) and the availability of both sand and silt in the source area. Sand-sheet facies A, located above the basal facies, is characterized by meter-scale gently dipping sigmoidal strata, having a maximum dip angle of $140^{\circ} / 13^{\circ}$. The dune facies at the top of the formation is separated from sandsheet facies A by a coarse-grained bounding surface. The dune facies strata have a maximum dip angle of $350^{\circ} / 37^{\circ}$. However, the strike of the strata show considerable variability, in line with the inferred parabolic shape of the dunes. The top of this crossstratified sand is marked by a 0.3 -m-thick paleopodsol (Paleosol B1, Figure 5b; hidden by a small ledge on Figure 5a). Except for some faint horizontal lamination, sedimentary structures in the overlying sand from the Kootwijk Formation are obliterated by several soil levels (e.g., Paleosol B2, Figure 5b).

\section{RESULTS}

\section{Ground-penetrating radar}

GPR data were sampled along a line that was located $5 \mathrm{~m}$ from the section wall (Figure 6) and had a length of $35 \mathrm{~m}$. The line was sampled with two frequencies (Table 2). On the 100-MHz radar section (Figure 7a), some of the largest features of the unit are visible. At a depth of about $6 \mathrm{~m}$, two gently left-dipping reflections represent the boundary between the eolian sands and the tidal clays. These reflections become discontinuous and less pronounced towards the left, which may be a result of increasing reflector depth or a decreasing change in grain-size or water content at this reflector. Below the boundary, the electromagnetic signal is attenuated quickly and hence no deeper reflectors can be seen (1) Figure 7a). The sub-horizontal reflections above the 
sand-clay transition (2) Figure 7a) originate in sand-sheet facies B (Figure 5b). Above this GPR facies, numerous discontinuous and mostly right-dipping reflections (3) Figure 7a) mark sand-sheet facies A (Figure 5b). The gently left-dipping reflections (4) Figure $7 \mathrm{a}$ ) that overly this unit mark the cross-stratified dune facies (Figure $5 b$ ). The paleosol between the Twente and Kootwijk formations (Figure 5b) is delineated by the continuous, dipping reflection at an approximate depth of $1.5 \mathrm{~m}$ (5) Figure 7a). At the top of the radar section, the two horizontal reflections ( (6) Figure 7a) represent the direct air- and groundwaves.

On the 200-MHz radar section (Figure 7b), more detail is visible, especially in the 2 to 4-m depth range. However, depth of penetration has decreased and both the sand-clay transition and sand-sheet facies B are only barely visible in the profile (1) and (2) Figure 7b). The reflections representing sand-sheet facies A (3) Figure 7b) generally dip to the right as expected (Figure 5b). Left-dipping reflections (4) Figure $7 b$ ) mark the overlying cross-bedded dune facies (Figure 5b). The paleosol at the base of the Kootwijk Formation (Figure 5b) is represented by the reflection at a depth of around $1.5 \mathrm{~m}$ (5) Figure 7b). The horizontal reflection between the paleosol and the two direct waves (@ Figure 7b) may represent either (horizontal) bedding or one of the discontinuous soil horizons B2 (Figure 5b).

\section{Textural characteristics}

Laser grain-size analyses (Konert and Vandenberghe, 1997) and thin sections (from lacquer peel OSL01) provide information on the sediment characteristics. The sandy intervals consist of fine to medium sand $(229.1 \mu \mathrm{m}$ to $287.5 \mu \mathrm{m})$ that is subrounded and moderately to well sorted. Pore space occasionally exceeds maximum grain-size, indicating rooting or burrowing. In the paleosol a large amount of organic material ( $\sim 5 \%$ of total sediment volume) occupies part of the pore space.

\section{Time-domain reflectometry and lacquer peels}

Lacquer peels were taken from representative parts of the wall covering the full height of the section (Table 3) and TDR data (Table 4) and sediment samples (Table 5) were then collected from these transects (Figure 5). Comparison of TDR diagrams with associated lacquer peels (Figure 8) illustrates several relationships between sediment characteristics and dielectric properties. The product $\varepsilon_{r} \mu_{r}$ (Equation (3)) increases from a baseline value of about 4 in the upper part of the section to almost 25 in its lower part. The baseline value of 4 represents the relative permittivity of dry sand, whereas the value of 25 is characteristic of the relative permittivity of water-saturated sand (Davis and Annan, 1989; Wensink, 1993), both having a relative magnetic permeability of unity. Following Equation (4), these values for $\varepsilon_{r}$ correspond to volumetric water contents of 0.055 and 0.4 , respectively. Numerous excursions in $\varepsilon_{r} \mu_{r}$ are superimposed on the general trend and most of these can be linked to features recorded in the lacquer peels. 
The paleosol at a depth of $1.8 \mathrm{~m}$ gives an increase in $\varepsilon_{r} \mu_{r}$ to about 8 (Figure $8 \mathrm{a}$ ). This is caused by the fact that organic material, present in this paleosol, holds water, which increases relative permittivity. Figure $8 \mathrm{~b}$ shows a similar response to organic matter when two individual cross-sets, with windblown organic material, cause the relative permittivity to increase. In the lower part of Figure $8 \mathrm{~b}$ and the upper part of Figure $8 \mathrm{c}$, several iron-oxide bands, identified in the lacquer peels, result in sharp increases in $\varepsilon_{r} \mu_{r}$. Most of these iron bands follow depositional bedding, but some, such as the band at a depth of $4.4 \mathrm{~m}$ (Figure $8 \mathrm{~b}$ ), cross-cut the bedding, indicating a diagenetic origin of the iron bands. Since the $\varepsilon_{r} \mu_{r}$ peaks typically occur directly on top of these cemented and less permeable layers, they may be caused by stagnating water occupying pore space, resulting in an increase of $\varepsilon_{r}$. Alternatively, an increase in the relative magnetic permeability, caused by the presence of iron-oxide minerals, may bring about the observed peaks in $\varepsilon_{r} \mu_{r}$. The small iron-oxide-related excursions in the TDR $\log$ associated with lacquer peel OSL02 (Figure $8 \mathrm{~b}$ ) are superimposed on a baseline value for $\varepsilon_{r} \mu_{r}$ of about 4 (volumetric water content of 0.055 ). In the TDR log associated with lacquer peel OSL03 (Figure 8c), the amplitude of the iron-oxide-related excursions is higher. This suggests that, since water saturation increases downward in lacquer peel OSL03, stagnating water and thus relative permittivity is the main cause for the increase in $\varepsilon_{r} \mu_{r}$.

In the zone where average water content remains low and changes in $\varepsilon_{r} \mu_{r}$ are caused by either organic material or iron oxide (Figures $8 \mathrm{a}$ and $8 \mathrm{~b}$ ), it is noteworthy that none of these changes can be related directly to grain-size. In lacquer peel OSL02, large-scale cross-bedding is obvious but none of the bedding planes cause $\varepsilon_{r} \mu_{r}$ to change significantly, except where organic material or iron is present. For example, the gravel layer at $2.85 \mathrm{~m}$ depth does not result in any change in $\varepsilon_{r} \mu_{r}$ in the TDR log (Figure 8b). In contrast, $\varepsilon_{r} \mu_{r}$ fluctuates significantly where water saturation increases (Figure 8c). In this case, fluctuations that coincide with the presence of iron-oxide bands as well as sedimentary structures are superimposed on a general increase in $\varepsilon_{r} \mu_{r}$ with depth. Here, fine-grained layers from sand-sheet facies B (Figure 5) enhance capillary forces and therefore support changes in relative permittivity. Thus, GPR reflections from sedimentary structures, not related to mineralogical change, can be expected only when values for relative permittivity and volumetric water content exceed the baseline values of 4 and 0.055 , respectively.

\section{Synthetic radar traces}

Using the three TDR logs (Figure 8), one log covering the full section was compiled. From this composite TDR $\log$ and the lacquer peels, giving information on $\varepsilon_{r} \mu_{r}$ and sediment characteristics respectively, four dielectric impedance models were constructed, each focusing on a particular characteristic of the section (Figure 9). Using the four impedance models, 1-D synthetic GPR traces were constructed. The layered impedance models have a depth scale whereas the synthetic traces have a time scale. 
Since the product of relative permittivity and relative magnetic permeability, and thus the wave velocity, varies over depth, the relative thickness of the layers also varies.

Figure 9a shows the graph of $\varepsilon_{r} \mu_{r}$ versus depth that was used as input for the different impedance models. Figure $9 \mathrm{~b}$ represents the simplest situation with a basic value of 4 and two excursions: the paleosol and the increase in $\varepsilon_{r} \mu_{r}$ above the sand-clay transition. In the synthetic radar traces, all layer boundaries appear as radar reflections, and there are also multiples of earlier reflections (indicated by arrows). The situation in Figure 9c represents the slightly more complex paleosol (as found in the TDR logs) and a stepped increase in $\varepsilon_{r} \mu_{r}$ towards the sand-clay transition. The thin layer, with a $\varepsilon_{r} \mu_{r}$ value of 4, within the paleosol leads to overlapping waveforms (especially in the $100-\mathrm{MHz}$ synthetic trace). Figure $9 \mathrm{~d}$ focuses on the small excursions in the TDR logs caused by the iron-oxide bands and windblown organic matter. In the $200-\mathrm{MHz}$ synthetic trace, all events can be distinguished, but in the 100-MHz synthetic trace, overlapping waveforms produce a more complicated pattern. The sediment model combining Figures 9c and 9d leads to highly complicated synthetic radar traces with overlapping waveforms and multiples (Figure 9e).

\section{DISCUSSION AND CONCLUSION}

Various reasons exist for changes in $\varepsilon_{r} \mu_{r}$ and thus for radar reflections, but changes in relative permittivity are the most important factor. The relative permittivity is predominantly controlled by water content, which is due to the large $\varepsilon_{r}$ contrast between air and water. Relative permittivity is 1 for air and 80 for water, whereas it is 4-6 for most sedimentary minerals (Davis and Annan, 1989). The volume fractions of the different constituents that form the sediment determine $\varepsilon_{r}$. Consequently, the sediment porosity as well as the ability of the sediment to hold water are important factors controlling the relative permittivity (Knoll and Knight, 1994). When water content is high, such as in the lower part of the section (Figure 8c), smaller pores cause both water content and relative permittivity to increase. When water content is low, such as in the higher part of the section (Figures $8 \mathrm{a}$ and $8 \mathrm{~b}$ ), the relative permittivity is controlled by the ability of the sediment to retain water. Both organic material, which holds water, and fine-grained sediment, which enhances capillary forces, cause water content as well as relative permittivity to increase. The role of relative magnetic permeability in the GPR reflection process is less clear. Von Hippel (1954) reported a relative magnetic permeability of 1.09 for magnetite-bearing sediment, which would result in an increase in $\varepsilon_{r} \mu_{r}$ from 4 to 4.4 for dry sandy sediment. When viewing this result in light of the data from the present study in which iron-oxide-related excursions in $\varepsilon_{r} \mu_{r}$ from 4 to about 6 were found (Figure 8b), one must conclude that most of the increase is caused by increasing $\varepsilon_{r}$, and thus water content, rather than $\mu_{r}$. The required relative magnetic permeability values of 1.5 have not been reported in the literature. This suggests that the possible influence of iron oxides, enhancing $\mu_{r}$, is much smaller than that of water, enhancing $\varepsilon_{r}$. 
In the zone with a baseline value of 4 for $\varepsilon_{r} \mu_{r}$, none of the changes can be related directly to grain size (Figures $8 \mathrm{a}$ and $8 \mathrm{~b}$ ). This explains the poorly defined boundary (i.e., gravel layer in Figure $8 \mathrm{~b}$ ) between the cross-stratified dune facies and sand-sheet facies A on the GPR images. Thus, when volumetric water content does not exceed 0.055 , grain size is not important as a cause of GPR reflections. However, numerous reflections in the zone just below the paleosol reflect sedimentary bedding of sandsheet facies A and the dune facies (Figure 7). Both windblown organic material and iron-oxide bands increase $\varepsilon_{r} \mu_{r}$ and could cause these reflections. Some reflections, however, dip in the direction opposite to that of the sedimentary structures. This is shown for example by the reflection at position $9 \mathrm{~m}$ at 4 meters depth in the $100 \mathrm{MHz}$ section (Figure 7a) and the reflection at position $15 \mathrm{~m}$ at 3 meters depth in the $200 \mathrm{MHz}$ section (Figure $7 b$ ). These reflections are most likely caused by iron-oxide bands that cross-cut sedimentary bedding.

The TDR logs could be used to calculate detailed synthetic radar traces. Owing to the non-vertical quarry wall, the depth in the dielectric impedance model, and consequently the time in the synthetic GPR traces, is overestimated by about 20 percent. Nevertheless, the synthetic traces (Figure 9) can be compared with the actual GPR sections (Figure 7). Waveforms that overlap in part in the synthetic traces (Figure 9b), due to the complex paleosol, are also present in the actual GPR sections. This is well exemplified in the $200 \mathrm{MHz}$ section between position 10 and 20 meters at a depth of 1 to 1.5 meters (Figure $7 b$ ). In Figure 9d, the small excursions in the TDR logs caused by the windblown organic matter and iron-oxide bands were modeled. This zone is difficult to compare with the actual radar sections as the variability in thickness and intensity of the iron-oxide bands is high and the changes in $\varepsilon_{r} \mu_{r}$ are small. Nevertheless, the reflection strengths in the synthetic traces and actual GPR sections match quite well. The increase in water content towards the sand-clay transition was modeled in the synthetic traces using a simplified three-step increase in $\varepsilon_{r} \mu_{r}$ (Figure 9c). The three reflection events in the synthetic traces that result from this tripartition show a clear decrease in amplitude with depth but cannot be linked to the actual radar sections because the TDR logs show a higher variability in $\varepsilon_{r} \mu_{r}$ (Figure 9a). Nevertheless, synthetic GPR traces can help in understanding the various reflections in actual GPR sections.

Not all GPR reflections can be matched with events on TDR logs, lacquer peels and 1-D synthetic images. The internal lateral variability of the facies is the main problem in correlating these data sets. Within the 5-m distance from the GPR sections to the quarry face, both the geometry and the depth of the facies, as well as the water content, could have changed laterally. In spite of the above, this study shows that the combination of TDR and sedimentological analysis is a very useful technique for qualifying and quantifying $\varepsilon_{r} \mu_{r}$ in the subsurface and achieving a better insight into the origin of GPR reflections. 


\section{ACKNOWLEDGEMENTS}

The Netherlands Institute of Applied Geoscience (NITG-TNO) and the Physical Geography Department of the University of Amsterdam are thanked for kind permission to use their equipment. The late Thom Roep guided us to the outcrop and was instrumental in conducting the fieldwork. We also gratefully acknowledge the help of Fabricio `scalebar' De Jonge and Kim Cohen (Utrecht University), Evert Slob (Delft University of Technology) and Albrecht Weerts and Stefan Dekker (University of Amsterdam) during the fieldwork. The work was supported financially by NITG-TNO and the Vrije Universiteit Industrial Associates in Sedimentology. Useful comments were made by Mark Dekkers (Utrecht University), Adrian Immenhauser and Kees Kasse (Vrije Universiteit) and Jan Van Der Kruk (Delft University of Technology). The manuscript benefited from critical reviews by Joep Storms (Delft University of Technology) and Sytze Van Heteren (Vrije Universiteit) on an earlier version and by Steve Cardimona (University of Missouri-Rolla) and Peter Huggenberger (University of Basel).

\section{REFERENCES}

Annan, A. P., Cosway, S. W. \& Redman, J. D. (1991) Water table detection with ground penetrating radar. In: 61st Annual International Meeting Society Exploration Geophysicists, Expanded Abstracts, pp. 494-496.

Arcone, S. A. (1984) Field observations of electromagnetic pulse propagation in dielectric slabs. Geophysics, 49(10), 1763-1773.

Asprion, U. \& Aigner, T. (1997) Aquifer architecture analysis using groundpenetrating radar: Triassic and Quaternary examples (S. Germany). Environmental Geology, 31, 66-75.

Beres, M., Green, A., Huggenberger, P. \& Horstmeyer, H. (1995) Mapping the architecture of glaciofluvial sediments with three-dimensional georadar. Geology, 23(12), 1087-1090.

Bracco Gartner, G. L. \& Schlager, W. (1999) Discriminating between onlap and lithologic interfingering in seismic models of outcrops. AAPG Bulletin, 83(6), 952-971.

Brewster, M. L. \& Annan, A. P. (1994) Ground-penetrating radar monitoring of a controlled DNAPL release: $200 \mathrm{MHz}$ radar. Geophysics, 59(8), 1211-1221.

Bridge, J. S., Collier, R. E. L. \& Alexander, J. (1998) Large-scale structure of Calamus River deposits (Nebraska, USA) revealed using ground-penetrating radar. Sedimentology, 45, 977-986.

Brisco, B., Pultz, T. J., Brown, R. J., Topp, G. C., Hares, M. A. \& Zebchuck, W. D. (1992) Soil moisture measurement using portable dielectric probes and time domain reflectometry. Water Resources Research, 28(5), 1339-1346. 
Bristow, C. S., Pugh, J. \& Goodall, T. (1996) Internal structure of aeolian dunes in Abu Dhabi determined using ground-penetrating radar. Sedimentology, 43, 995-1003.

Carcione, J. M. (1996) Ground-penetrating radar: wave theory and numerical simulation in lossy anisotropic media. Geophysics, 61(6), 1664-1677.

Cardimona, S. J., Clement, W. P. \& Kadinsky-Cade, K. (1998) Seismic reflection and ground-penetrating radar imaging of a shallow aquifer. Geophysics, 63(4), 1310-1317.

Casper, D. A. \& Kung, K.-J. S. (1996) Simulation of ground-penetrating radar waves in a 2-D soil model. Geophysics, 61(4), 1034-1049.

Dalton, F. N., Herkelrath, W. N., Rawlins, D. S. \& Rhoades, J. D. (1984) Timedomain reflectometry: Simultaneous measurement of soil water content and electrical conductivity with a single probe. Science, 224, 989-990.

Davis, J. L. \& Annan, A. P. (1989) Ground-penetrating radar for high resolution mapping of soil and rock stratigraphy. Geophysical Prospecting, 37, 531-551.

Fagin, S. W. (1991) Seismic modeling of geologic structures - applications to exploration problems. Society Exploration Geophys., Tulsa, 267 pp.

Fellner-Feldegg, H. (1969) The measurement of dielectrics in the time domain. The Journal of Physical Chemistry, 73(3), 616-623.

Fokkema, J. T., Fokkema, E., Beekman, S. \& Slob, E. C. (2001) Analysis of georadar reflection responses. In: 7th International Congress of the Brazilian Geophysical Society, Salvador-Bahia, Brazil.

Gawthorpe, R. L., Collier, R. E. L., Alexander, J., Leeder, M. R. \& Bridge, J. S. (1993) Ground penetrating radar: application to sandbody geometry and heterogeneity studies. In: Characterisation of fluvial and aeolian reservoirs (Ed. by C. P. North and D. J. Prosser), 73, pp. 421-432. Spec. Publ. Geol. Soc. Lond.

Heimovaara, T. J. (1993) Design of triple-wire time domain reflectometry probes in practice and theory. Soil Science Society of America Journal, 57, 1410-1417.

Heimovaara, T. J. \& Bouten, W. (1990) A computer-controlled 36-channel time domain reflectometry system for monitoring soil water contents. Water Resources Research, 26(10), 2311-2316.

Heimovaara, T. J., De Winter, E. J. G., Van Loon, W. K. P. \& Esveld, D. C. (1996) Frequency-dependent dielectric permittivity from 0 to $1 \mathrm{GHz}$ : Time domain reflectometry measurements compared with frequency domain network analyzer measurements. Water Resources Research, 32(12), 3603-3610.

Heimovaara, T. J., Focke, A. G., Bouten, W. \& Verstraten, J. M. (1995) Assessing temporal variations in soil water composition with time domain reflectometry. Soil Science Society of America Journal, 59(3), 689-698.

Hollender, F. \& Tillard, S. (1998) Modeling ground-penetrating radar wave propagation and reflection with the Jonscher parameterization. Geophysics, 63(6), 1933-1942. 
Huggenberger, P. (1993) Radar facies: recognition of facies patterns and heterogeneities within Pleistocene Rhine gravels, NE Switzerland. In: Braided Rivers (Ed. by J. L. Best and C. S. Bristow), Geological Society Special Publication, No. 75, pp. 163-176. Geological Society, London.

Jol, H. M. \& Smith, D. G. (1991) Ground penetrating radar of northern lacustrine deltas. Canadian Journal of Earth Sciences, 28, 1939-1947.

Kasse, C. (1988) Early-Pleistocene tidal and fluviatile environments in the southern Netherlands and northern Belgium. Ph.D. thesis, Vrije Universiteit, 190 pp.

Knoll, M. D. \& Knight, R. (1994) Relationships between dielectric and hydrogeologic properties of sand-clay mixtures. In: 5th International Conference on Ground Penetrating Radar, Vol. 1, pp. 45-61. Waterloo Centre for Groundwater Research, Kitchener, Ontario, Canada.

Konert, M. \& Vandenberghe, J. (1997) Comparison of laser grain size analysis with pipette and sieve analysis: a solution for the underestimation of the clay fraction. Sedimentology, 44, 523-535.

Mayer, L. A. (1979) Deep sea carbonates: acoustic, physical and stratigraphic properties. Journal of Sedimentary Petrology, 49(3), 819-836.

Mayer, L. A. (1980) Deep-sea carbonates: physical property relationships and the origin of high-frequency acoustic reflectors. Marine Geology, 38, 165-183.

Neal, A. \& Roberts, C. L. (2000) Applications of ground-penetrating radar (GPR) to sedimentological, geomorphological and geoarchaeological studies in coastal environments. In: Coastal and estuarine environments: sedimentology, geomorphology and geoarchaeology (Ed. by K. Pye and J. R. L. Allen), Geological Society Special Publication, No. 175, pp. 139-171. Geological Society, London.

Olhoeft, G. R. \& Capron, D. E. (1994) Petrophysical causes of electromagnetic dispersion. In: 5th international conference on Ground-penetrating radar, pp. 145-152, Kitchener, Ontario, Canada.

Powers, M. H. (1997) Modeling frequency-dependent GPR. The Leading Edge, 16(11), 1657-1662.

Roth, K., Schulin, R., Flühler, H. \& Attinger, W. (1990) Calibration of time domain reflectometry for water content measurement using a composite dielectric approach. Water Resources Research, 26(10), 2267-2273.

Schwan, J. (1991) Palaeowetness indicators in a Weichselian Late Glacial to Holocene aeolian succession in the southwestern Netherlands. Z. Geomorph. N.F., Suppl.-Bd. 90, 155-169.

Sensors\&Software. (1996) pulse EKKO synthetic radargram user's guide, pp. 1-18. Sensors\&Software, Mississauga, ON, Canada.

Stafleu, J. \& Schlager, W. (1995) Pseudo-unconformities in seismic models of large outcrops. Geologische Rundschau, 84, 761-769. 
Stafleu, J. \& Sonnenfeld, M. D. (1994) Seismic models of a shelf-margin depositional sequence: upper San Andres Formation, Last Chance Canyon, New Mexico. Journal of Sedimentary Research, 64(4), 481-499.

Sutinen, R. (1992) Glacial deposits, their electrical properties and surveying by image interpretation and ground penetrating radar. Ph.D. thesis, University of Oulu, University of Wisconsin-Madison, 123 pp.

Theimer, B. D., Nobes, D. C. \& Warner, B. G. (1994) A study of the geoelectrical properties of peatlands and their influence on ground-penetrating radar surveying. Geophysical Prospecting, 42(3), 179-209.

Topp, G. C., Davis, J. L. \& Annan, A. P. (1980) Electromagnetic determination of soil water content: measurements in coaxial transmission lines. Water Resources Research, 16(3), 574-582.

Topp, G. C., Davis, J. L. \& Annan, A. P. (1982) Electromagnetic determination of soil water content using TDR: I. applications to wetting fronts and steep gradients. Soil Science Society of America Journal, 46, 672-678.

Van Heteren, S., FitzGerald, D. M., McKinlay, P. A. \& Buynevich, I. V. (1998) Radar facies of paraglacial barrier systems: coastal New England, USA. Sedimentology, 45, 181-200.

Van Overmeeren, R. A. (1998) Radar facies of unconsolidated sediments in The Netherlands: A radar stratigraphy interpretation method for hydrogeology. Journal of Applied Geophysics, 40, 1-18.

Von Hippel, A. R. (1954) Dielectric Materials and Applications. John Wiley and Sons, New York, 438 pp.

Wensink, W. A. (1993) Dielectric properties of wet soils in the frequency range 13000 MHz. Geophysical Prospecting, 41, 671-696.

Zegelin, S. J., White, I. \& Jenkins, D. R. (1989) Improved field probes for soil water content and electrical conductivity measurement using time domain reflectometry. Water Resources Research, 25(11), 2367-2376. 


\section{TABLES}

Table 1 - GPR setup and wave parameters. The wavelengths in dry, moist, and saturated sand are based on an electromagnetic wave velocity of $0.15 \mathrm{mns}^{-1}, 0.12 \mathrm{mns}^{-}$ ${ }^{1}$, and $0.06 \mathrm{mns}^{-1}$, respectively. The resolution was estimated using the generally accepted one-quarter wave length axiom.

\begin{tabular}{|c|c|c|c|c|c|c|c|c|}
\hline \multirow[b]{2}{*}{ System } & \multirow[b]{2}{*}{$\begin{array}{l}f \\
{[\mathrm{MHz}]}\end{array}$} & \multirow[b]{2}{*}{$\begin{array}{l}\text { Antenna } \\
\text { separation } \\
{[\mathrm{m}]}\end{array}$} & \multicolumn{2}{|c|}{ Dry sand } & \multicolumn{2}{|c|}{ Moist sand } & \multicolumn{2}{|c|}{ Wet sand } \\
\hline & & & $\lambda[\mathrm{m}]$ & $\begin{array}{l}\text { Resolutio } \\
\mathrm{n}[\mathrm{m}]\end{array}$ & $\lambda[\mathrm{m}]$ & $\begin{array}{l}\text { Resolutio } \\
\mathrm{n}[\mathrm{m}]\end{array}$ & $\lambda[\mathrm{m}]$ & $\begin{array}{l}\text { Resolutio } \\
\mathrm{n}[\mathrm{m}]\end{array}$ \\
\hline PE 100 & 100 & 1.00 & 1.500 & 0.375 & 1.200 & 0.300 & 0.600 & 0.150 \\
\hline PE 100 & 200 & 0.50 & 0.750 & 0.188 & 0.600 & 0.150 & 0.300 & 0.075 \\
\hline $\begin{array}{c}\mathrm{PE} \\
1000\end{array}$ & 450 & 0.25 & 0.333 & 0.083 & 0.267 & 0.067 & 0.133 & 0.033 \\
\hline $\begin{array}{c}\text { PE } \\
1000\end{array}$ & 900 & 0.17 & 0.167 & 0.042 & 0.133 & 0.033 & 0.067 & 0.017 \\
\hline
\end{tabular}

Table 2 - Characteristics and locations of GPR measurements.

\begin{tabular}{llllllll}
\hline Line & $\begin{array}{l}\text { Distance } \\
\text { to wall } \\
{[\mathrm{m}]}\end{array}$ & $f[\mathrm{MHz}]$ & Mode & $\begin{array}{l}\mathrm{X}_{0} \\
{[\mathrm{~m}]}\end{array}$ & $\begin{array}{l}\mathrm{X}_{\max } \\
{[\mathrm{m}]}\end{array}$ & $\begin{array}{l}\mathrm{X}_{\text {tot }} \\
{[\mathrm{m}]}\end{array}$ & $\Delta \mathrm{X} \mathrm{[ \textrm {m } ]}$ \\
\hline OSR01 & 5 & 100,200 & Reflectio & 0 & 35 & 35 & 0.25 \\
& & 100,200 & $\mathrm{n}$ & 11 & - & $10,7.8$ & 0.20 \\
\hline
\end{tabular}

$f=$ frequency.

Table 3 - Locations and sizes of lacquer peels.

\begin{tabular}{lllll}
\hline Name & $\begin{array}{c}\mathrm{Y}_{\text {top }} \\
{[\mathrm{m}]}\end{array}$ & $\mathrm{Y}_{\text {bot }}[\mathrm{m}]$ & $\begin{array}{c}\mathrm{Y}_{\text {tot }} \\
{[\mathrm{m}]}\end{array}$ & $\mathrm{X}[\mathrm{m}]$ \\
\hline OSL01 & 0.0 & 2.3 & 2.3 & 12.5 \\
OSL02 & 2.1 & 4.7 & 2.6 & 11.0 \\
OSL03 & 3.7 & 5.6 & 1.9 & 4.5 \\
\hline
\end{tabular}


Table 4-Characteristics and locations of TDR measurements.

\begin{tabular}{lllllllll}
\hline Name & $\begin{array}{l}\text { TDR } \\
\text { section } \\
\text { (Fig. 5) }\end{array}$ & $\begin{array}{l}\mathrm{Y}_{0} \\
{[\mathrm{~m}]}\end{array}$ & $\begin{array}{l}\mathrm{Y}_{\max } \\
{[\mathrm{m}]}\end{array}$ & $\begin{array}{l}\mathrm{Y}_{\text {tot }} \\
{[\mathrm{m}]}\end{array}$ & $\begin{array}{l}\Delta \mathrm{Y} \\
{[\mathrm{m}]}\end{array}$ & $\begin{array}{l}\text { Probe } \\
\text { Length } \\
{[\mathrm{m}]}\end{array}$ & $\mathrm{X}[\mathrm{m}]$ & Location in grid \\
\hline z970605.00 & 1 & 0.8 & 1.95 & 1.15 & 0.050 & 0.10 & 12.5 & Lacquer peel \\
1 & 1 & 0.8 & 2.00 & 1.20 & 0.050 & 0.05 & 12.5 & OSL01 \\
z970605.00 & 1 & 1.6 & 2.30 & 0.70 & 0.025 & 0.05 & 12.5 & Lacquer peel \\
2 & 2 & 2.1 & 4.70 & 2.60 & 0.050 & 0.05 & 11.0 & OSL01 \\
z970606.00 & 3 & 3.7 & 6.00 & 2.30 & 0.050 & 0.05 & 4.5 & Lacquer peel \\
3 & & & & & & & & OSL01 \\
z970606.00 & & & & & & & & Lacquer peel \\
4 & & & & & & & & OSL02 \\
z970606.00 & & & & & & & & OSL03 peel \\
5 & & & & & & & & \\
\hline
\end{tabular}

Table 5 - Locations of thin section samples.

\begin{tabular}{llll}
\hline Name & $\mathrm{Y}[\mathrm{m}]$ & $\begin{array}{l}\mathrm{X} \\
{[\mathrm{m}]}\end{array}$ & Location in grid \\
\hline OSS1 & 0.6 & 12.5 & Lacquer peel \\
OSS2 & 1.6 & 12.5 & OSL01 \\
OSS3 & 1.6 & 12.5 & $\begin{array}{l}\text { Lacquer peel } \\
\text { OSL01 } \\
\end{array}$ \\
& & & $\begin{array}{l}\text { Lacquer peel } \\
\text { OSL01 }\end{array}$ \\
\hline
\end{tabular}




\section{FIGURE CAPTIONS}

Figure 1 - (a) Ground-penetrating radar setup and method and (b) resulting radar section.

Figure 2 - (a) Diagram of time-domain reflectometry (TDR) equipment, (b) field example, and (c) resulting wave form. The travel time $\left(\Delta t_{s}\right)$ along the probe, with length $L_{p}$, determines electromagnetic properties (equation (7)).

Figure 3 - Map of The Netherlands showing location of study area.

Figure 4 - Schematic stratigraphic column for quarry Boudewijn, Ossendrecht. Data from Kasse (1988), Schwan (1991) and the present study. GF = Griendtsveen Formation, $\mathrm{EMH}=$ Early and Middle Holocene, Ad = Allerød.

Figure 5 - (a) Picture of section wall showing the locations of lacquer peels and TDR sections. (b) Schematic representation of sedimentary and pedogenic structures. In the Twente Formation, left of lacquer peel OSL02, several diagenetic iron-oxide bands that cross-cut depositional bedding are problematic for the interpretation of sedimentary structures.

Figure 6 - Sketch to illustrate location of measurements in the Boudewijn quarry.

Figure 7 - Radar sections for line OSR01 (left) and interpretation (right); (a) $100 \mathrm{MHz}$, (b) $200 \mathrm{MHz}$. The outlined part corresponds with the interpreted section shown in Figure 5. CMPs indicate that the electromagnetic wave velocity was $0.11 \mathrm{mns}^{-1}$ in the upper highly resistive subunit, and averaged $0.09 \mathrm{mns}^{-1}$ for the total unit. Radar sections for line OSR01 are printed with a velocity of $0.09 \mathrm{mns}^{-1}$. Since this velocity is an average for the entire unit, the plot is stretched and compressed in its higher and lower parts respectively. Average vertical exaggeration is 1.4. The numbered labels in the interpreted radar sections refer to the text and represent: (1) tidal clays, (2) sand-sheet facies B, (3) sand-sheet facies A, (4) dune facies, (5) paleosol, (6) overlapping air- and groundwaves, and (7) reflections dipping in the opposite direction to the sedimentary structures.

Figure 8 - Lacquer peels and associated TDR measurements. (a) TDR section 1 and lacquer peel OSL01, (b) TDR section 2 and lacquer peel OSL02, and (c) TDR section 3 and lacquer peel OSL03. Lacquer peels are printed in mirror image, such that the structures are shown in their true orientation in the quarry wall.

Figure 9 - (a) Composite TDR log for the complete quarry section. Layered dielectric impedance models, constructed from this log, and resulting 1-D synthetic radar traces; (b) simple, (c) soil, (d) iron and windblown organic matter, and (e) combination. Arrows indicate multiples. Note that vertical scales are in depth for the TDR log and layered sediment models and in time for the synthetic radar traces. 


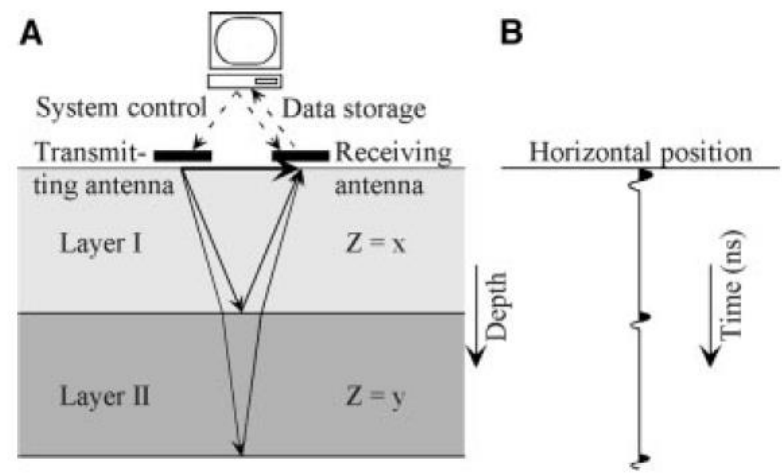

Figure 1 - (a) Ground-penetrating radar setup and method and (b) resulting radar section. 

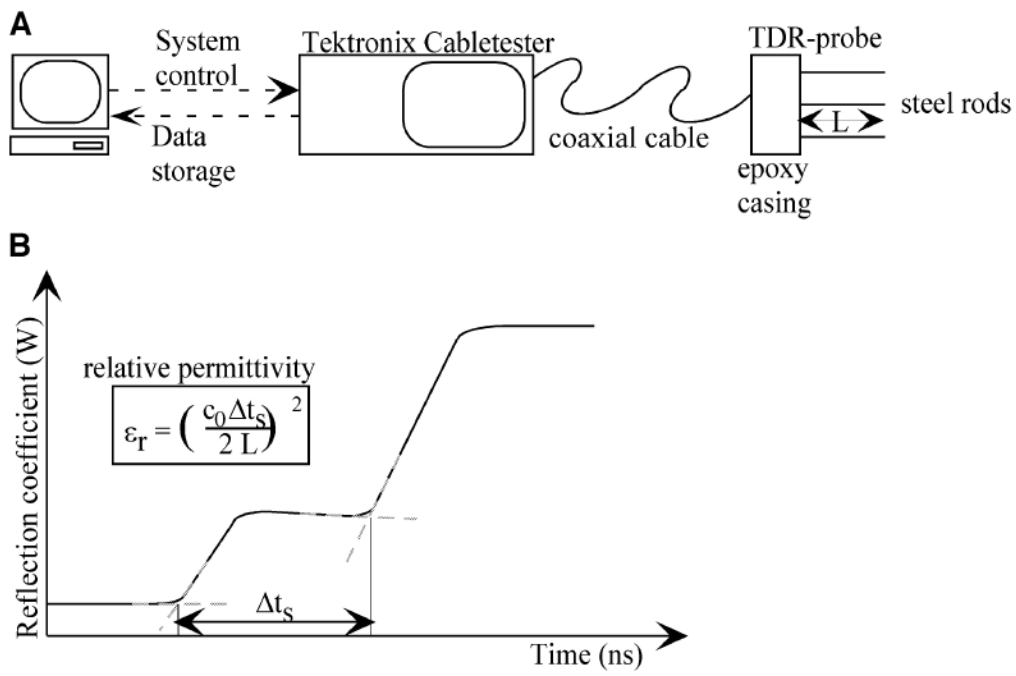

Figure 2 - (a) Diagram of time-domain reflectometry (TDR) equipment, (b) field example, and (c) resulting wave form. The travel time $\left(\Delta t_{s}\right)$ along the probe, with length $L_{p}$, determines electromagnetic properties (equation (7)). 


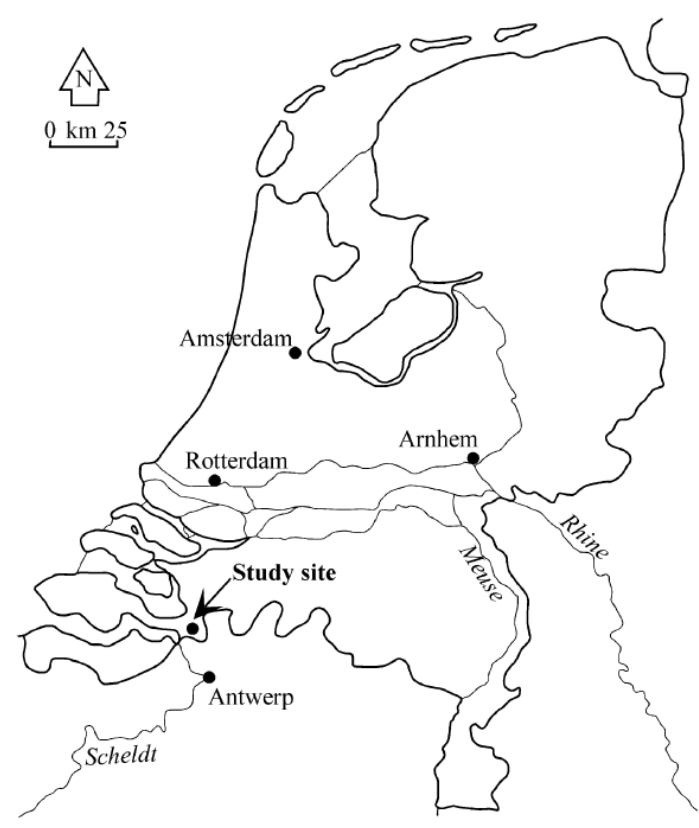

Figure 3 - Map of The Netherlands showing location of study area. 


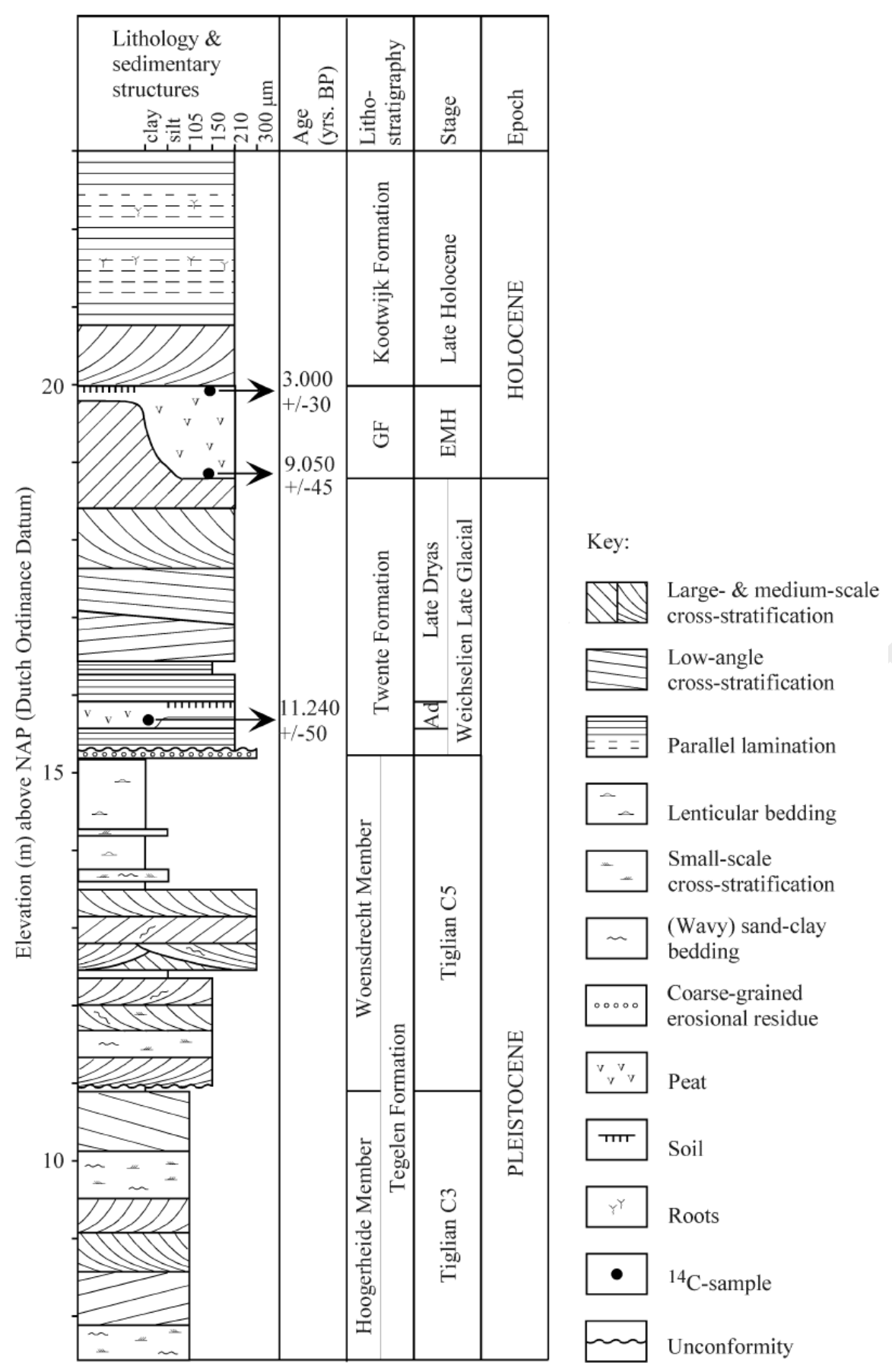

Figure 4 - Schematic stratigraphic column for quarry Boudewijn, Ossendrecht. Data from Kasse (1988), Schwan (1991) and the present study. GF = Griendtsveen Formation, EMH = Early and Middle Holocene, Ad = Allerød. 

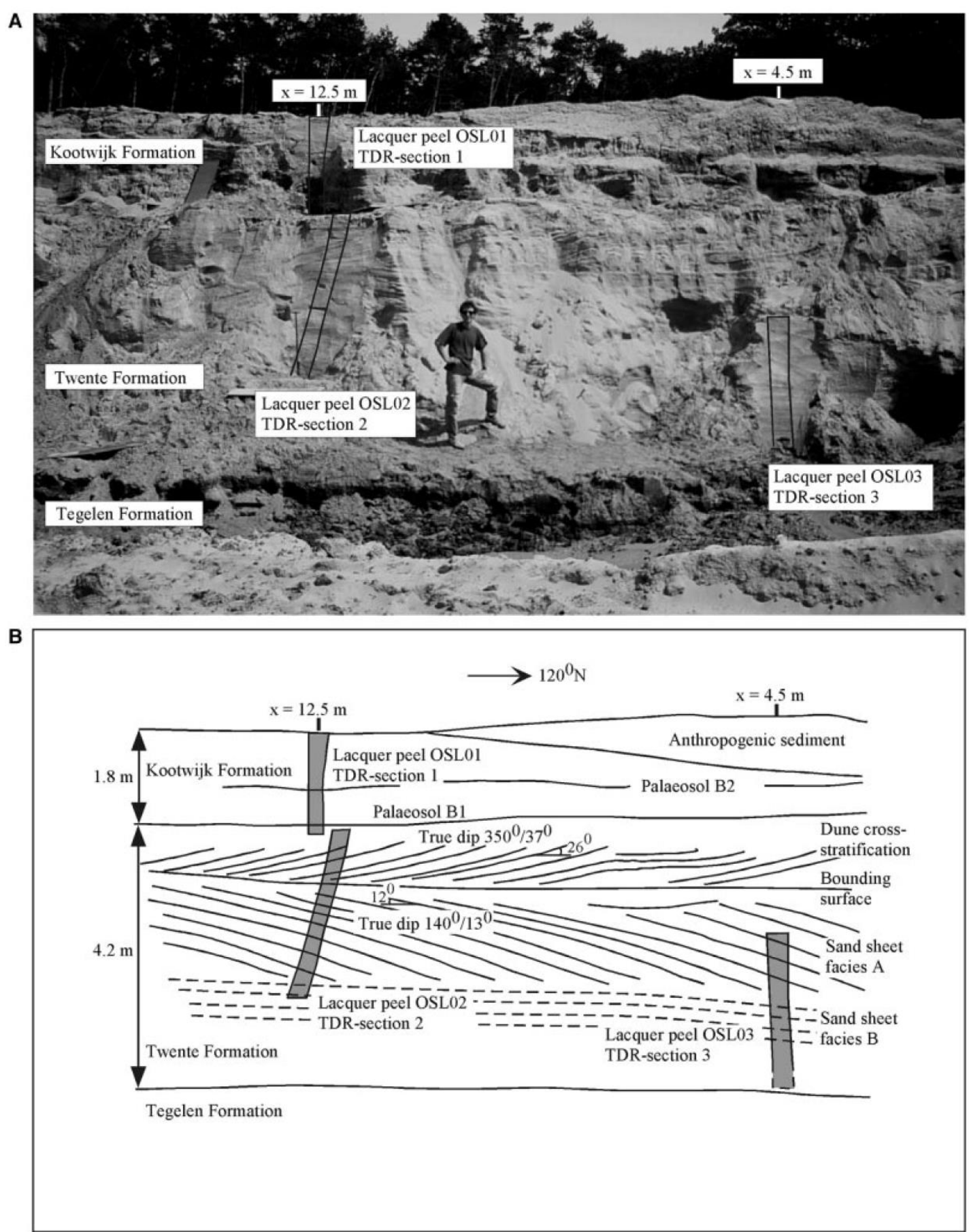

Figure 5 - (a) Picture of section wall showing the locations of lacquer peels and TDR sections. (b) Schematic representation of sedimentary and pedogenic structures. In the Twente Formation, left of lacquer peel OSL02, several diagenetic iron-oxide bands that cross-cut depositional bedding are problematic for the interpretation of sedimentary structures. 


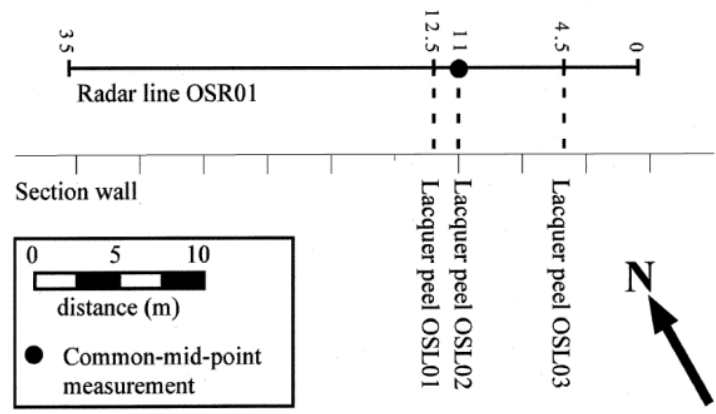

Figure 6 - Sketch to illustrate location of measurements in the Boudewijn quarry. 

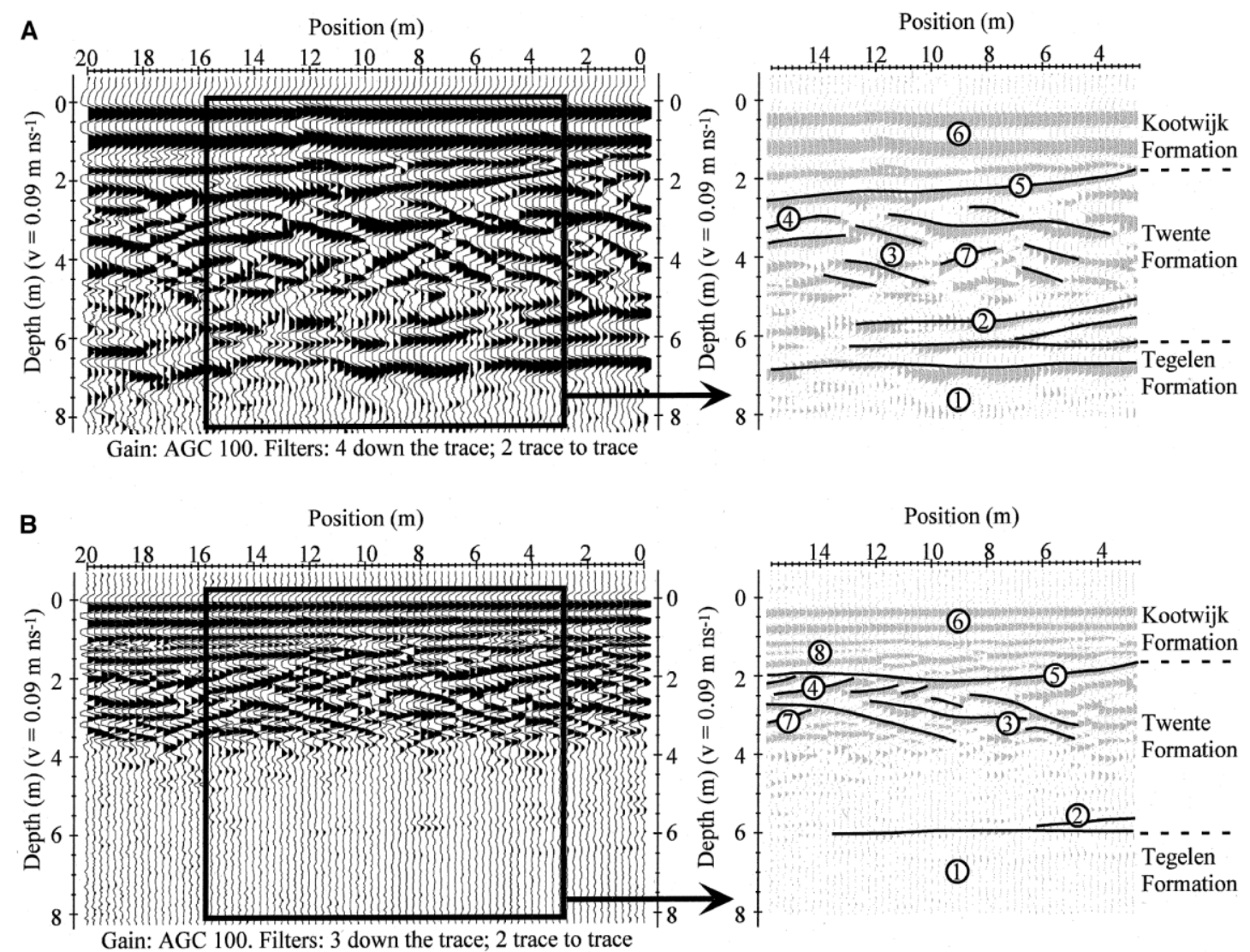

Figure 7 - Radar sections for line OSR01 (left) and interpretation (right); (a) 100 MHz, (b) $200 \mathrm{MHz}$. The outlined part corresponds with the interpreted section shown in Figure 5. CMPs indicate that the electromagnetic wave velocity was $0.11 \mathrm{mns}^{-1}$ in the upper highly resistive subunit, and averaged $0.09 \mathrm{mns}^{-1}$ for the total unit. Radar sections for line OSR01 are printed with a velocity of $0.09 \mathrm{mns}^{-1}$. Since this velocity is an average for the entire unit, the plot is stretched and compressed in its higher and lower parts respectively. Average vertical exaggeration is 1.4. The numbered labels in the interpreted radar sections refer to the text and represent: (1) tidal clays, (2) sandsheet facies B, (3) sand-sheet facies A, (4) dune facies, (5) paleosol, (6) overlapping airand groundwaves, and (7) reflections dipping in the opposite direction to the sedimentary structures. 

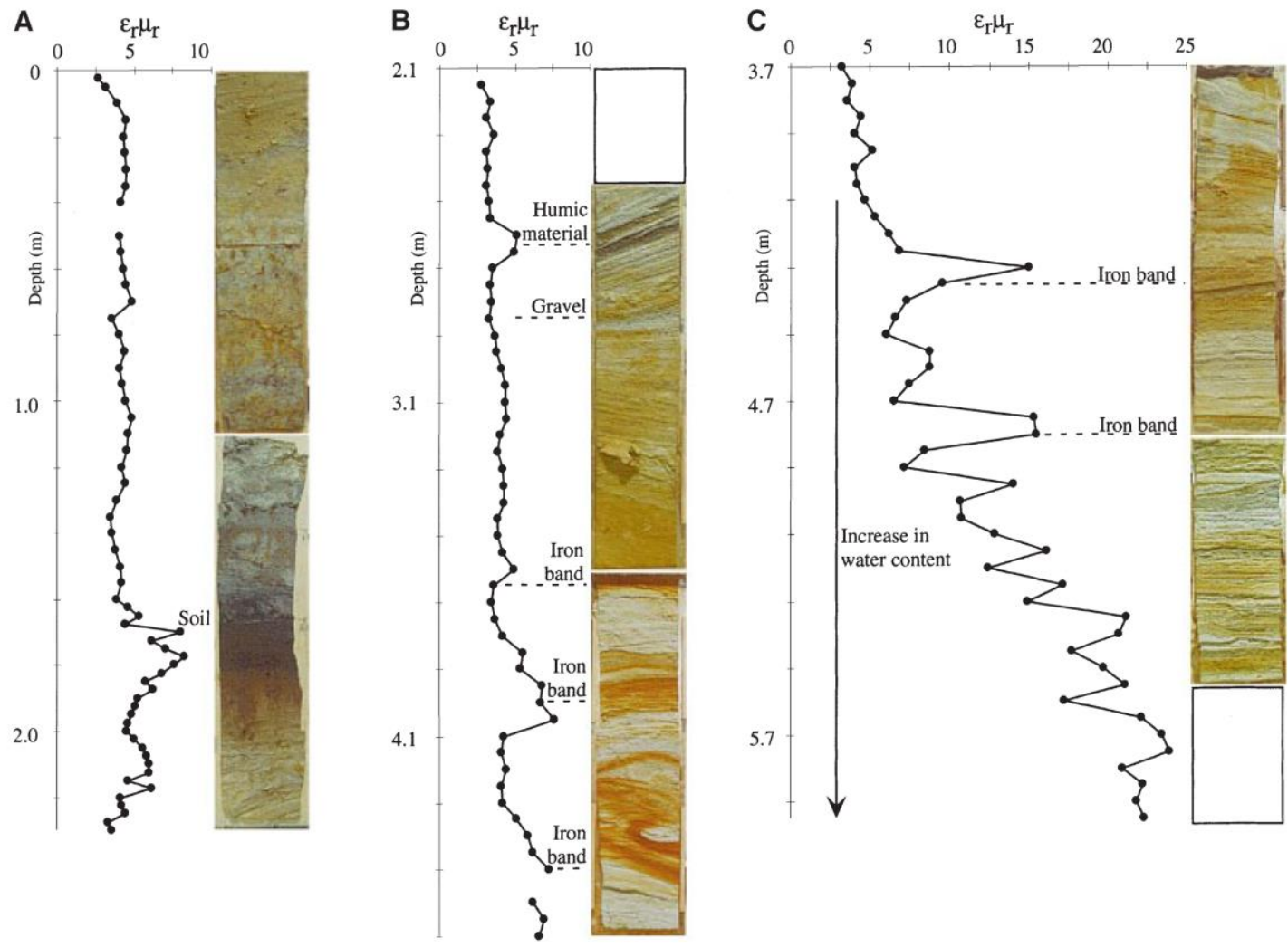

Figure 8 - Lacquer peels and associated TDR measurements. (a) TDR section 1 and lacquer peel OSL01, (b) TDR section 2 and lacquer peel OSL02, and (c) TDR section 3 and lacquer peel OSL03. Lacquer peels are printed in mirror image, such that the structures are shown in their true orientation in the quarry wall. 


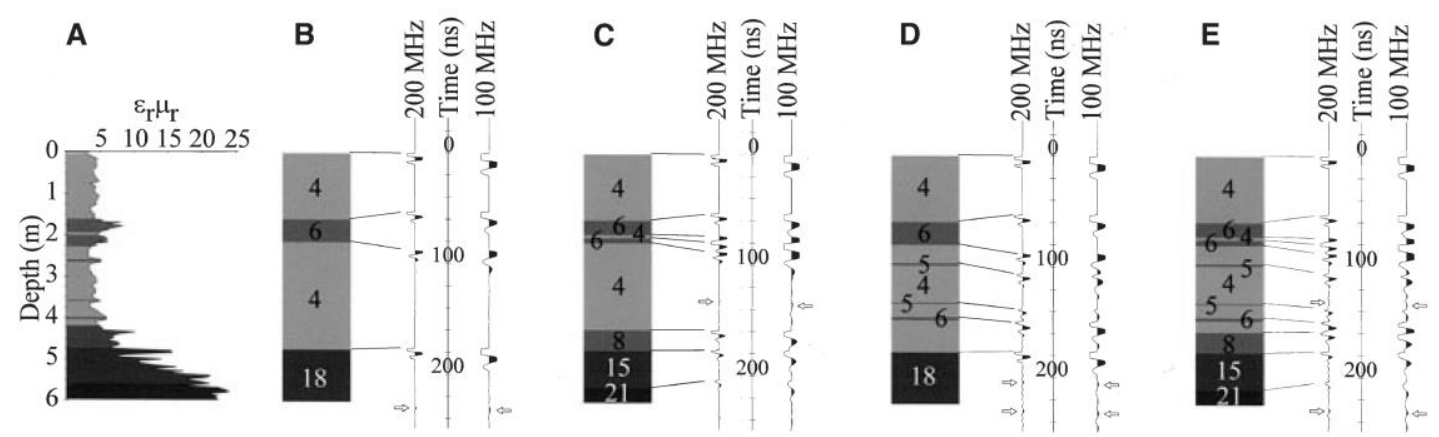

Figure 9- (a) Composite TDR log for the complete quarry section. Layered dielectric impedance models, constructed from this log, and resulting 1-D synthetic radar traces; (b) simple, (c) soil, (d) iron and windblown organic matter, and (e) combination. Arrows indicate multiples. Note that vertical scales are in depth for the TDR log and layered sediment models and in time for the synthetic radar traces. 